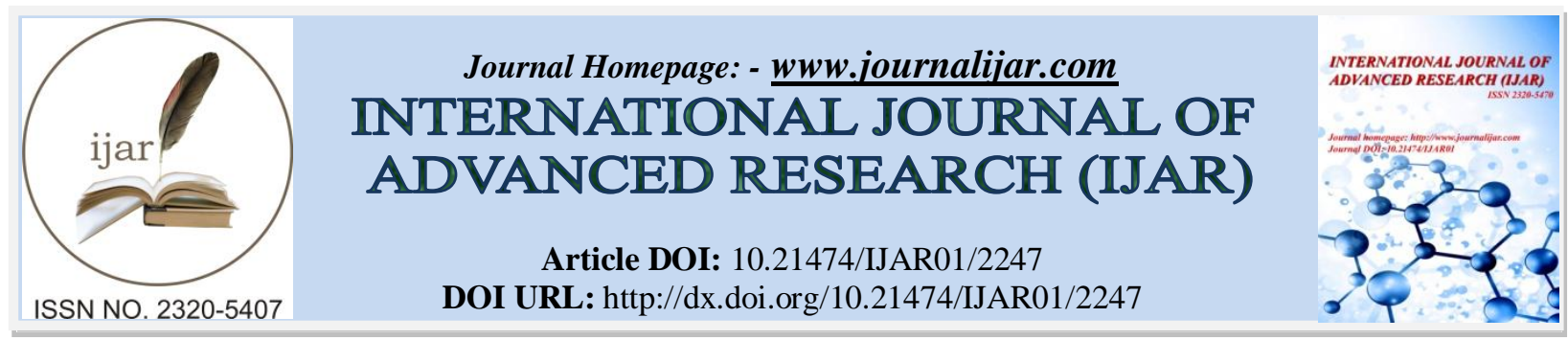

RESEARCH ARTICLE

\title{
EMPLOYEE SATISFACTION ON LABOUR WELFARE MEASURES IN THE SELECT TEXTILE UNITS - A STUDY ON GUNTUR DISTRICT IN A.P.
}

Dr. P. C. Sai Babu' ${ }^{1}$ and Goli Gurunadham ${ }^{2}$.

1. Reader, Dept.of Commerce, Bapatla College of Arts \& Science, Andhra Pradesh,India.

2. Asst.Professor, Dept.of AS\&H, Tirumala Engineering College, Guntur,Andhra Pradesh,India.

\section{Manuscript Info}

Manuscript History

Received: 29 September 2016

Final Accepted: 30 October 2016

Published: November 2016

Key words:-

Lablour Welfare Measures, Employee

Perception, Level of Satisfaction

\begin{abstract}
The welfare measures and schemes form an integral part of Personnel and HR Management in any organization will go a long way in ensuring the desired goals. In turn this will enhance the productivity of the organization. Job satisfaction focuses on employee's attitudes toward their jobs and organizational commitment focuses on their attitudes toward the overall organization. This paper examines the research question that Labour Welfare Measures have a strong correlation with the level of satisfaction among employees. The present study adopts the descriptive research design for conducting the research work and sampling was done through Stratified Random sampling method. The study involves both primary and secondary data. Primary data was collected by administering a structured questionnaire and personal interview method. The sample size was fixed at 248. The data analysis was done by applying statistical tools like ANOVA and Multiple-Regression Analysis. The proposed alternate hypothesis was tested and proved significant. It shows that there is a strong correlation between the implementation of labour welfare measures and the level of satisfaction among the employees of select textile units in Guntur District of A.P.
\end{abstract}

Copy Right, IJAR, 2016,. All rights reserved.

\section{Introduction:-}

With the growth of industrialization and mechanization, it has acquired added importance, a happy and contented work force is an asset for the industrial prosperity of any nation, Labour welfare is nothing but the maintenance function of personnel in the sense that it is directed specifically to the preservation of employee health and attitudes. In other words, it contributes to the maintenance of employee morale. The welfare services in an industry is to improve the living and working conditions of workers and their families because the workers well-being cannot be achieved in isolation of his family. Labour welfare, though it has been proved to contribute to efficiency in production, is expensive. Each employer depending on his priorities gives varying degrees of importance to labour welfare. It is because the government is not sure that all employers are progressive minded and will provide basic welfare measures that it introduces statutory legislation from time to time to bring about some measure of uniformity in the basic amenities available to industrial workers. Obviously, there is some creation and stimulation in the maintenance function just as there is some maintenance in all other operative personnel functions. But the primary emphasis in employee service programme has been on maintaining an employee's favourable attitude towards his work and work environment. 
The welfare measures and schemes form an integral part of Personnel and HR Management in any organization will go a long way in ensuring the desired goals. In turn this will enhance the productivity of the organization. The welfare measures are designed and systematized by the organization through statutory bodies like trade unions. The labour departments of the government insist upon minimum amenities to be implemented in any organization. This will ensure that minimum standards that are required for an employee to carry out the duties and perform functions to the extent of satisfaction.

\section{Significance Of The Study:-}

The purpose of providing welfare amenities is to bring about development of the whole personality of the worker -his social, psychological, economic, moral, cultural and intellectual development to make him a good worker, a good citizen and a good member of the family. These facilities may be provided voluntarily by progressive and enlightened entrepreneurs at their own accord out of their realization of social responsibility towards labour, or statutory provisions may compel them to make these facilities available; or these may be undertaken by the government or trade unions, if they have the necessary funds for the purpose. Labour welfare is a very broad term, covering social security and such other activities as medical aid, crèches, canteens, recreation, housing, adult education, arrangements for the transport of labour to and from the work place. It may be noted that not only intra-mural but also extra-mural, statutory as well as nonstatutory activities, undertaken by any of the three agencies- the employers, trade unions or the government- for the physical and mental development of the worker, both as a compensation for wear and tear that he undergoes as a part of the production process and also to enable him to sustain and improve upon the basic capacity of contribution to the processes of production, which are all the species of the longer family encompassed by the term 'labour welfare'. The concept of labour welfare has been evolved in order to extend a measure of social assistance to the section of workers toiling in various sectors. For this end, separate legislations have been enacted by parliament to setup welfare funds to provide housing, medical, education and recreational facilities to workers employed. Thus the aspects of labour welfare measures do have their significant role in the promotion of better industrial relations, environment and industrial harmony in the society.

\section{Scope Of The Study:-}

Industrial progress depends on satisfied labour force and in this connection the importance of labour welfare was accepted long back.. Labour welfare concept is basically based on human values, where each citizen has a right to work in a congenial environment with no hazards to his health on reasonable wages and other terms and conditions of employment. The days are over when labour was considered to be a commodity. When a worker joins industry he has to work in an entire strange atmosphere, creating problems of adjustment. Having a satisfied workforce is very much essential for smooth working of every organization. So this study is conducted to know whether the workers are aware of the provisions of labour welfare and their level of satisfaction towards the welfare practices provided by textile industries in Andhra Pradesh. The outcome of the study may help the administration and policy makers to differentiate the satisfying factors from dissatisfying and to take effective steps to improve the labour welfare in the textile industry.

\section{Review Of Literature:-}

Seenivasan and Rajendran (2011) studied Spinning mill employee's trade union in Virudhunagar district with a sample size of 200 using stratified random sampling technique. It is found that trade unions have economic motives and security. The trade unions are continuously striving for the purpose of maintaining or improving the conditions of their work. It was clear that the workers join trade union to fight for their wage, job security, and increasing bargaining capacity. It was suggested that workers may be motivated by paying for over time wages, providing compensatory leave for the extra time of work, improving the working conditions in the mills with adequate facilities, etc.

Manju et al (2012) for their study titled "A study on Labour Welfare measures in Salem Steel Plant" with objectives to study about the various labour welfare provided by the Salem Steel Plant to its employees; to study the attitudes of the workers towards the various welfare provided by the industry; to study the impact of labour welfare measures on the productivity of the industry; to suggest recommendation on the basic of which the labour welfare can be improved. The data were collected from the blue collar and white collar employees. Data were collected through the questionnaire with a sample of 105 respondents chosen stratified random sampling. The results showed that most of the respondents are satisfied with canteen facilities. Half of the respondents are satisfied in role of welfare officer.

Ramasatyanarayana (2012) made a study titled "Labour Welfare Measures in Cement Industries in India" with objectives to study the various welfare measures available in the organization; to know the satisfaction levels 
employees about labour welfare measures provided by the organization; to offer suggestions to improve the standard of labour welfare in the organization. Data were collected through the questionnaire with a sample of 92 respondents chosen convenience sampling. The results showed that 90 per cent of the respondents are satisfied transport facilities, medical facilities, drinking water, rest room, sports and recreational facilities. Majority of the respondents are moderately satisfied with the subsidized canteen food and supply of uniforms. Most of the respondents are highly dissatisfied for not paying annual bonus and no facilities of cooperative store.

Narsimha Reddy. Y (2013) In his work on industrial relations and welfare measures in the BHEL suggested that workers participation in management clubbed with effective implementation of labour legislations do promote healthy industrial relations in the organization. The work also suggested that multiplicity of unions hampered the industrial peace in the organization.

Ravindra. K.B (2013) Labour welfare and social security has got a lot of significance with Public Sector, Private Sector and also Multinational Companies. Labour welfare activities in an industrialized society have far reaching impact not only on the work force but also on all facets of human resources. Labour welfare includes all such activities which not only secure existential necessities but also ensures improvement in the spiritual, emotional and other aspects of a worker. The aspect of labour welfare requires an honest and serious approach that money and environment given to employees never go waste. A happy employee is a productive employee. A study on labour welfare and social security is an effort to be perfected in the art of managing people and in these days the most important management is people's management. Welfare schemes should be regarded as a wise investment which should and usually does bring a profitable return in the form of greater efficiency. The study provides a detailed insight in to the various aspects of labour welfare and social security in Indian Industries.

\section{Objectives Of The Study:-}

1. To study the significance of labour welfare measures in the textile units of Andhra Pradesh.

2. To assess the employee perception on identified labour welfare measures and to measure their impact on the level of satisfaction among employees of the sample units.

3. To identify any possible deficiencies and weaknesses pertaining to labour welfare practices in the sample textile units.

4. To offer suitable suggestions for effective implementation of labour welfare measures in the sample textile units.

\section{Hypothesis:-}

Based on the above objectives, the following alternate hypothesis was formulated and tested.

$\mathrm{Ha}_{1}$ : Implementation of Labour welfare practices do have a strong correlation with the level of satisfaction among employees.

Test Applied: ANOVA and Multiple-Regression Analysis.

\section{Research Methodology:-}

The present study adopts the descriptive research design for conducting the research work and sampling was done through Stratified Random Sampling method. The study involves both primary and secondary data. Primary data was collected by administering a structured questionnaire and personal interview method. Secondary data was collected through verifying published documents, organizational publications of Textile Industrial Units and other relevant material in publication form. The sample size was fixed at 248. The data analysis was done by applying statistical tools like ANOVA and Multiple-Regression Analysis.

\section{Data Analysis And Findings}

TABLE 1 - AGE AND LEVEL OF SATISFACTION ON WELFARE MEASURES

\begin{tabular}{|c|c|c|c|c|c|c|c|c|}
\hline \multirow[t]{3}{*}{ Age } & \multicolumn{6}{|c|}{ Level of satisfaction } & \multicolumn{2}{|l|}{ Total } \\
\hline & \multicolumn{2}{|l|}{ Low } & \multicolumn{2}{|c|}{ Medium } & \multicolumn{2}{|l|}{ High } & Frequency & $\%$ \\
\hline & Freq & $\%$ & Freq & $\%$ & Freq & $\%$ & & \\
\hline Below 30 & 1 & 4.35 & 4 & 2.92 & 2 & 2.27 & 7 & 2.82 \\
\hline 31 to 40 & 1 & 4.35 & 79 & 57.66 & 57 & 64.77 & 137 & 55.24 \\
\hline 41 to 50 & 5 & 21.74 & 49 & 35.77 & 28 & 31.82 & 82 & 33.07 \\
\hline Above 50 & 16 & 69.57 & 5 & 3.65 & 1 & 1.14 & 22 & 8.87 \\
\hline Total & 23 & 100 & 137 & 100 & 88 & 100 & 248 & 100 \\
\hline
\end{tabular}

Freq - Frequency 
The above table no- 1 shows that majority of the respondents do fall under the age category of 31 to 40 years followed by the age category in between 41 to 50 years. Only a minority of respondents do fall under the age category of below 30 years. A small fraction of the respondents fell under the age category of above 50 years. The respondents under the age group 31 to 40 years revealed that they have the highest level of satisfaction (64.77\%)with regard to Labour Welfare Measures in their organization. This shows that majority of the respondents are in their vital age to perform the organizational activities with vigor and commitment.

TABLE 2 - MARITAL STATUS AND LEVEL OF SATISFACTION

\begin{tabular}{|l|l|l|l|l|l|l|l|l|}
\hline \multirow{3}{*}{ Marital Status } & \multicolumn{4}{|l}{ Level of satisfaction } & \multicolumn{2}{l|}{ Medium } & High & Total \\
\cline { 2 - 10 } & Low & \multicolumn{2}{|l|}{} & Freq & $\%$ \\
\cline { 2 - 10 } & Freq & $\%$ & 135 & $\%$ & Freq & $\%$ & & \\
\hline Married & 23 & 100.00 & 135 & 98.54 & 82 & 93.18 & 240 & 96.77 \\
\hline Unmarried & & & 2 & 1.46 & 6 & 6.82 & 8 & 3.23 \\
\hline Total & 23 & 100.00 & 137 & 100.00 & 88 & 100.00 & 248 & 100.00 \\
\hline
\end{tabular}

The above table no-2 depicts the marital status of the respondents. It shows that majority of the respondents (96.77\%) were married. Only a micro fraction of the respondents fell under the unmarried category. The table further shows that the married category have the highest level of satisfaction(93.18\%) with regard to Labour Welfare practices in their organization.

TABLE 3 - EDUCATIONAL STATUS AND LEVEL OF SATISFACTION

\begin{tabular}{|c|c|c|c|c|c|c|c|c|}
\hline \multirow[t]{3}{*}{ Education } & \multicolumn{6}{|c|}{ Level of satisfaction } & \multicolumn{2}{|c|}{ Total } \\
\hline & \multicolumn{2}{|l|}{ Low } & \multicolumn{2}{|c|}{ Medium } & \multicolumn{2}{|l|}{ High } & Freq & $\%$ \\
\hline & Freq & $\%$ & Freq & $\%$ & Freq & $\%$ & & \\
\hline Up to SSC & 1 & 4.35 & 3 & 2.19 & 3 & 3.41 & 7 & 2.82 \\
\hline Diploma & 3 & 13.04 & 17 & 12.41 & 22 & 25.00 & 42 & 16.94 \\
\hline ITI & 8 & 34.78 & 66 & 48.18 & 59 & 67.05 & 133 & 53.63 \\
\hline Graduate & 4 & 17.39 & 29 & 21.17 & 4 & 4.55 & 37 & 14.92 \\
\hline Professional & 7 & 30.43 & 22 & 16.06 & - & - & 29 & 11.69 \\
\hline Total & 23 & 100.00 & 137 & 100.00 & 88 & 100.00 & 248 & 100.00 \\
\hline
\end{tabular}

The above table no-3 shows the educational status of the respondents and their level of satisfaction towards labour welfare practices in their organizations. It shows that majority of the respondents (53.63\%) do fall under the ITI category followed by diploma courses. Only a minor fraction of respondents represent the graduates and professionals category. The respondents under the SSC category were very low. The table further shows that the respondent under the ITI category expressed their maximum level of satisfaction $(67.05 \%)$ towards the labour welfare practices in their organizations.

TABLE 4 - DEPARTMENT AND LEVEL OF SATISFACTION (TWO WAY TABLE)

\begin{tabular}{|c|c|c|c|c|c|c|c|c|}
\hline \multirow[t]{3}{*}{ Department } & \multicolumn{6}{|c|}{ Level of satisfaction } & \multicolumn{2}{|c|}{ Total } \\
\hline & \multicolumn{2}{|c|}{ Low } & \multicolumn{2}{|c|}{ Medium } & \multicolumn{2}{|l|}{ High } & Freq & $\%$ \\
\hline & Freq & $\%$ & Freq & $\%$ & Freq & $\%$ & & \\
\hline Non Technical & 14 & 60.87 & 67 & 48.91 & 33 & 37.50 & 114 & 45.97 \\
\hline Technical & 9 & 39.13 & 70 & 51.09 & 55 & 62.50 & 134 & 54.03 \\
\hline Total & 23 & 100.00 & 137 & 100.00 & 88 & 100.00 & 248 & 100.00 \\
\hline
\end{tabular}

The above table no- 4 shows the department wise expression of level of satisfaction towards labour welfare practices in the organization. Majority of the respondents (54.03\%) fall under the technical class in terms of their department and majority of the respondents under technical department $(62.50 \%)$ expressed that they are having the high level of satisfaction towards labour welfare practices being implemented in their organizations.

TABLE 5 - EXPERIENCE OF THE RESPONDENTS AND LEVEL OF SATISFACTION

\begin{tabular}{|c|c|c|c|c|c|c|c|c|}
\hline \multirow[t]{3}{*}{ Experience in Years } & \multicolumn{6}{|c|}{ Level of satisfaction } & \multicolumn{2}{|c|}{ Total } \\
\hline & \multicolumn{2}{|l|}{ Low } & \multicolumn{2}{|c|}{ Medium } & \multicolumn{2}{|l|}{ High } & \multirow[t]{2}{*}{ Freq } & \multirow[t]{2}{*}{$\%$} \\
\hline & Freq & $\%$ & Freq & $\%$ & Freq & $\%$ & & \\
\hline Up to 5 & & & 3 & 2.19 & 1 & 1.14 & 4 & 1.61 \\
\hline 6 to 10 & & & 3 & 2.19 & 1 & 1.14 & 4 & 1.61 \\
\hline 11 to 15 & 1 & 4.35 & 75 & 54.74 & 56 & 63.64 & 132 & 53.23 \\
\hline 16 to 20 & & & 26 & 18.98 & 24 & 27.27 & 50 & 20.16 \\
\hline Above 20 & 22 & 95.65 & 30 & 21.90 & 6 & 6.82 & 58 & 23.39 \\
\hline Total & 23 & 100.00 & 137 & 100.00 & 88 & 100.00 & 248 & 100.00 \\
\hline
\end{tabular}


The above table no-5 shows the experience of the respondents and their level of satisfaction towards the labour welfare practices in their organizations. It shows that majority of the respondents $(52.23 \%)$ fall under the category of 11 to 15 years of experience expressing that they have the higher levels of satisfaction $(63.64 \%)$ followed by the respondents under the experience category of 16 to 20 years.

TABLE 6 - DISIGNATION OF EMPLOYEES AND LEVEL OF SATISFACTION

\begin{tabular}{|c|c|c|c|c|c|c|c|c|}
\hline \multirow[t]{3}{*}{ Type } & \multicolumn{6}{|c|}{ Level of satisfaction } & \multicolumn{2}{|c|}{ Total } \\
\hline & \multicolumn{2}{|l|}{ Low } & \multicolumn{2}{|c|}{ Medium } & \multicolumn{2}{|c|}{ High } & Freq & $\%$ \\
\hline & Freq & $\%$ & Freq & $\%$ & Freg & $\%$ & & \\
\hline Non - Executive & 15 & 65.22 & 114 & 83.21 & 87 & 98.86 & 216 & 87.10 \\
\hline Executive & 8 & 34.78 & 23 & 16.79 & 1 & 1.14 & 32 & 12.90 \\
\hline Total & 23 & 100.00 & 137 & 100.00 & 88 & 100.00 & 248 & 100.00 \\
\hline
\end{tabular}

The above table no. 6 shows the designation of the employees and their level of satisfaction towards the labour welfare practices in their Organizations. It shows that majority of the respondents $(87.10 \%)$ fall under non executive category. The table further shows that among the highly satisfied groups the non executive category comprises $98.86 \%$ and only $1.14 \%$ of the executive category are highly satisfied with the labour welfare practices being practiced in their organizations.

TABLE 7 - AWARENESS OF EMPLOYEES ON LABOUR WELFARE MEASURES AND THEIR LEVEL OF SATISFACTION

\begin{tabular}{|c|c|c|c|c|c|c|c|c|}
\hline \multirow{3}{*}{$\begin{array}{l}\text { Aware of HRM } \\
\text { practices }\end{array}$} & \multicolumn{6}{|c|}{ Level of satisfaction } & \multicolumn{2}{|c|}{ Total } \\
\hline & \multicolumn{2}{|l|}{ Low } & \multicolumn{2}{|c|}{ Medium } & \multicolumn{2}{|l|}{ High } & Freq & $\%$ \\
\hline & Freq & $\%$ & Freq & $\%$ & Freq & $\%$ & & \\
\hline No & & & 19 & 13.87 & 34 & 38.64 & 53 & 21.37 \\
\hline Yes & 23 & 100.00 & 118 & 86.13 & 54 & 61.36 & 195 & 78.63 \\
\hline Total & 23 & 100.00 & 137 & 100.00 & 88 & 100.00 & 248 & 100.00 \\
\hline
\end{tabular}

The above table no-7 shows the awareness of respondents towards Labour Welfare Measures and their level of satisfaction towards the labour welfare measures in their organizations. It shows that majority of the respondents $(78.63 \%)$ were well aware of the labour welfare measures and their level of satisfaction is very high $(61.36 \%)$ with regard to labour welfare measures in their organizations.

TABLE 8 - ANOVA

\begin{tabular}{|l|l|l|l|l|l|l|}
\hline $\mathrm{R}$ & R Square & & $\begin{array}{l}\text { Sum of } \\
\text { Squares }\end{array}$ & df & Mean Square & F \\
\hline \multirow{3}{*}{.825} & \multirow{2}{*}{0.68} & Regression & 13026.37 & 7 & 1628.30 & \multirow{2}{*}{$20.73 * *$} \\
\cline { 3 - 6 } & Residual & 18771.18 & 239 & 78.54 & \\
\cline { 2 - 6 } & Total & 31797.55 & 246 & & \\
\hline
\end{tabular}

The model summary table -8 reports the strength of the relationship between the model and the dependent variable. $\mathrm{R}$, the multiple correlation coefficients, is the linear correlation between the observed and model - predicted values of the dependent variable. Its large value indicates a strong relationship.

$\mathrm{R}$ Square, the coefficient of determination, is the squared value of the multiple correlation coefficients. It shows that about ninety five percent of the variation in profit is explained by the model. The ANOVA reports a significant $\mathrm{F}$ statistic, indicating that using the model is better than guessing the mean. As a whole, the regression does a good job of modeling satisfaction. The ANOVA table tests the acceptability of the model from a statistical perspective.

The model is linear because increasing the value of the $\mathrm{J}^{\text {th }}$ predictor by 1 unit increases the value of the dependent by bj units. In this section multiple regression analysis is used to explain the variation in the satisfaction (dependent variable) based on the variation over the variables (independent variable) designation, Age, Marital Status, Education, Department, Experience and Awareness on Labour Welfare Measures.

Therefore the multiple regression equation becomes.

$$
\begin{aligned}
& \mathrm{Y}=\mathrm{b}_{0}+\mathrm{b}_{1} \mathrm{X}_{1}+\mathrm{b}_{2} \mathrm{X}_{2}+\mathrm{b}_{3} \mathrm{X}_{3}+\mathrm{b}_{4} \mathrm{X}_{4}+\mathrm{b}_{5} \mathrm{X}_{5}+\mathrm{b}_{6} \mathrm{X}_{6}+\mathrm{b}_{7} \mathrm{X}_{7} \\
& \text { Dependent variable } \quad \mathrm{Y}=\text { Satisfaction level of Respondents on welfare } \\
& \text { Independent variable are } \mathrm{X}_{1}=\text { Age } \\
& \text { measures }
\end{aligned}
$$




$\begin{array}{lll}\mathrm{X}_{2} & = & \text { Marital Status } \\ \mathrm{X}_{3} & = & \text { Education } \\ \mathrm{X}_{4} & = & \text { Department } \\ \mathrm{X}_{5} & = & \text { Designation } \\ \mathrm{X}_{6} & = & \text { Experience } \\ \mathrm{X}_{7} & = & \text { Awareness on welfare measures }\end{array}$

TABLE 9- REGRESSION COEFFICIENTS

\begin{tabular}{|l|l|l|l|l|}
\hline & $\mathrm{B}$ & Std.Error & $\mathrm{t}$ & $\mathrm{P}$ \\
\hline (Constant) & 73.75 & 5.10 & 14.45 & $0.00^{* *}$ \\
\hline Age & -3.35 & 1.18 & -2.85 & $0.00^{* *}$ \\
\hline Marital Status & 13.72 & 3.21 & 4.28 & $0.00^{* *}$ \\
\hline Education & -3.31 & 0.75 & -4.40 & $0.00^{* *}$ \\
\hline Department & 1.58 & 2.16 & 0.73 & 0.47 \\
\hline Designation & 0.67 & 0.60 & 1.12 & 0.26 \\
\hline Experience & -2.67 & 0.88 & -3.04 & $0.00^{* *}$ \\
\hline Awareness & -3.76 & 1.50 & -2.51 & $0.01^{*}$ \\
\hline
\end{tabular}

Dependent Variable : Level of Satisfaction on Labour Welfare Measures

Multiple -Regression Analysis (Table -9) was used to explain the variation over the variables in select Textile Units. For this purpose eight of independent variables were selected to ascertain the relationship of them with the dependent variable namely the level of satisfaction of the employees. Multiple regression analysis was used for this purpose and the results highlight that seven independent variables shows significant association with the dependent variable. The independent variables are designation, age, marital status, education, department, experience and awareness on labour welfare measures.

The Regression row displays information about the variation accounted for the model. The Residual row displays information about the variation that is not accounted for the model. The regression sum of square is greater than residual sums of squares, which indicates that nearly ninety five percent of the variation in profit is explained by the model. The significance value of the F statistic is less than 0.05 , which means that the variation explained by the model is not due to chance. While the ANOVA table is a useful test of the model's ability to explain any variation in the dependent variable, it does not directly address the strength of that relationship.

Even though the model fit looks positive, the first section of the coefficients table- 9 shows that there are too many predictors in the model. There are several non - significant coefficients, indicating that these variables do not contribute much to the model. The non significant variables are department and designation.

This table shows the coefficients of the regression line. It states that the expected satisfaction level is equal to $\mathrm{Y}=73.75-3.35 \mathrm{X}_{1}+13.72 \mathrm{X}_{2}-3.31 \mathrm{X}_{3}+1.58 \mathrm{X}_{4}+0.67 \mathrm{X}_{5}-2.67 \mathrm{X}_{6}-3.76 \mathrm{X}_{7}$

Looking at the significance values we see that the variables Age, Marital Status, Education, Experience and Awareness are highly significant (less than .01).

\section{Result:-}

The proposed alternate hypothesis $\left(\mathrm{Ha}_{1}\right)$ was tested and proved significant. It shows that there is a strong correlation between labour welfare measures and the level of satisfaction among employees of select textile units.

\section{SUMMARY OF FINDINGS}

- Majority of the respondents are in the interval range of 31 to 40 years of age showing the tendency of vitality in their age to perform accordingly.

- Majority of the respondents under the age group of 31 to 40 years reveled that they have the highest level of satisfaction with regard to Labour welfare measures in the select organizations.

- Majority of the respondents fall under the category of married status and they had perceived the highest level of satisfaction with regard to Labour welfare measures in the select organizations.

- With regard to Educational status and Level of Satisfaction, the majority of respondents fall under ITI category and they had expressed their maximum level of satisfaction towards Labour welfare measures in the select organizations. 
- With regard to Department and level of satisfaction, the majority of the respondents fall under technical department and they had expressed the high level of satisfaction towards Labour welfare measures in the select organizations.

- With regard to Experience level of the respondents and their Level of Satisfaction, the majority of respondents fall under 11 to 15 years experience category and they had expressed their maximum level of satisfaction towards Labour welfare measures in the select organizations.

- With regard to Awareness level of the respondents on Labour welfare measures and their Level of Satisfaction, the majority of respondents felt that they are well aware of Labour welfare measures and they had expressed their maximum level of satisfaction towards Labour welfare measures in the select organizations.

- The Multiple regression analysis shows that among the Seven independent variables (Designation, Age, Marital Status, Education, Department, Experience and Awareness on Labour welfare measures) the five variables like Age, marital Status, Education, Experience and Awareness on Labour welfare measures are highly significant and strongly correlated to the dependent variable (Satisfaction level).

\section{Conclusion:-}

Today, implementation of labour welfare measures is much integrated and strategically involved. The most important task of labour welfare practices is to provide fair wages, good working conditions and realistic terms and conditions of employment. The labour welfare practices comprises both statutory and Non-statutory provisions as prescribed under the labour legislations formulated by the nation. Thus it can be concluded that employees in the sampling units do have a strong perception and satisfaction levels towards the labour welfare measures being implemented in their organizations.

\section{Suggestions:-}

1. The textile organizations has to create an environment that induces more awareness on the prevailing labour welfare practices in their organizations.

2. With regard to the Non-statutory labour welfare measures, the textile organizations have to take more initiatives in implementing the various provisions under the said acts for the well being of their employees.

3. Statutory welfare measures are to be implemented with due care and caution in order to increase the level of satisfaction among the respondents.

\section{References:-}

1. Seenivasan, V., \& Rajendran, S. (2011, August). Spinning mill employee's trade union: A study. Southern Economist, 12-14.

2. Manju, V., Jayanthi, K., \& Ashok Kumar, P. (2012, March). A study on Labour Welfare Measures in Salem Steel Plant. Asian Journal of Research in Social Science \& Humanities. 2 (3).

3. Ramasatyanarayana, M. (2012, July). Labour Welfare Measures in Cement Industries in India. International Journal of physical and social science, 2(7).

4. Narsimha Reddy .Y (2013), "Industrial Relations in Indian Public Sector: A case study of BHPV Ltd.”, Indian Journal of Labour Economics, Vol. XXVII.

5. Ravindra. K.B. (2013) - Labour Welfare Practices And Social Security In Industries - International Journal Of Research In Commerce, Economics \& Management, Vol. 03, Issue 06. 